\title{
Rhombencephalitis caused by Listeria monocytogenes with striking involvement of trigeminal nerve on MR imaging
}

\author{
Adriana Moro', Pedro Henrique de Campos Albino', Alisson Pittol Bresciani', \\ Marcus Victor de Oliveira', Melina Moré Bertotti², Rafael Martins Ferreira³ ${ }^{3}$ Luiz Paulo Queiroz ${ }^{4}$
}

The listeria rhombencephalitis is an uncommon and severe infection of the brainstem, usually occurring in healthy adults with a typical biphasic picture ${ }^{1}$. A prodrome of fever, headache, nausea and vomiting followed by abrupt neurological symptoms ${ }^{2}$. A stiff neck is present in half of the cases and positive culture in cerebrospinal fluid (CSF) in about 40\% of the cases. Mortality is high and serious sequelae are common ${ }^{2}$. We report a case of a patient with involvement of the brainstem and a favorable outcome.

\section{CASE}

A 65-year-old man presented with pain in right jaw, nuchal pain and right facial palsy, following gastroenteritis. The neurological exam revealed a palsy of VI and VII right cranial nerves, right hemifacial hypoesthesia, strength grade 3 , hyperreflexia, Babinski sign bilaterally, neck stiffness and axial ataxia. The CSF showed: 100 cells $/ \mathrm{mm}^{3}$ (95\% lymphocytes); protein $63 \mathrm{mg} / \mathrm{dL}$; glucose $95 \mathrm{mg} / \mathrm{dL}$; negative cultures for bacteria, fungi and acidfast bacilli. Magnetic resonance imaging (MRI) showed bilateral and asymmetric lesions involving the brainstem with a striking enhancement along the right trigeminal nerve and ipsilateral spinal trigeminal nucleus (Figure).

With the diagnostic suspicion of herpes zoster encephalitis, the patient was treated with acyclovir and was transferred to an intensive care unit due to respiratory failure 24 hours later.
Blood cultures showed the presence of Listeria monocytogenes later. Acyclovir was interrupted and intravenous ampicillin plus dexamethasone were initiated. The infection improved but the patient remained with severe neurological sequelae. The second MRI showed multiple hemorrhagic foci in the cerebellar hemispheres, brainstem, basal ganglia nuclei and capsular region. Mild signal abnormalities remained in the brainstem and cerebellar peduncles.

At four months he began walking and making sounds that were gradually replaced by full speech.

\section{DISCUSSION}

Listeria monocytogenes is a Gram-positive organism transmitted by consumption of contaminated food. The diagnosis can be delayed if no meningeal signs are presented in the beginning of the disease $\mathrm{e}^{4}$ as in our patient. Cultures of CSF and blood are positive in $41 \%$ and $61 \%$ of cases, respectively ${ }^{3}$. In our case only the blood culture was positive.

The CSF typically reveals an increased leukocyte count, with predominance of polymorphonuclear cells, increased protein, and normal glucose levels ${ }^{5}$. Our patient presented only a predominance of lymphomononuclear cells, maybe due to precoceous CSF examination.

MRI is important for the early detection of parenchymal lesions, therefore, being crucial for early diagnosis and follow-up ${ }^{5}$. The patient presented extensive le-
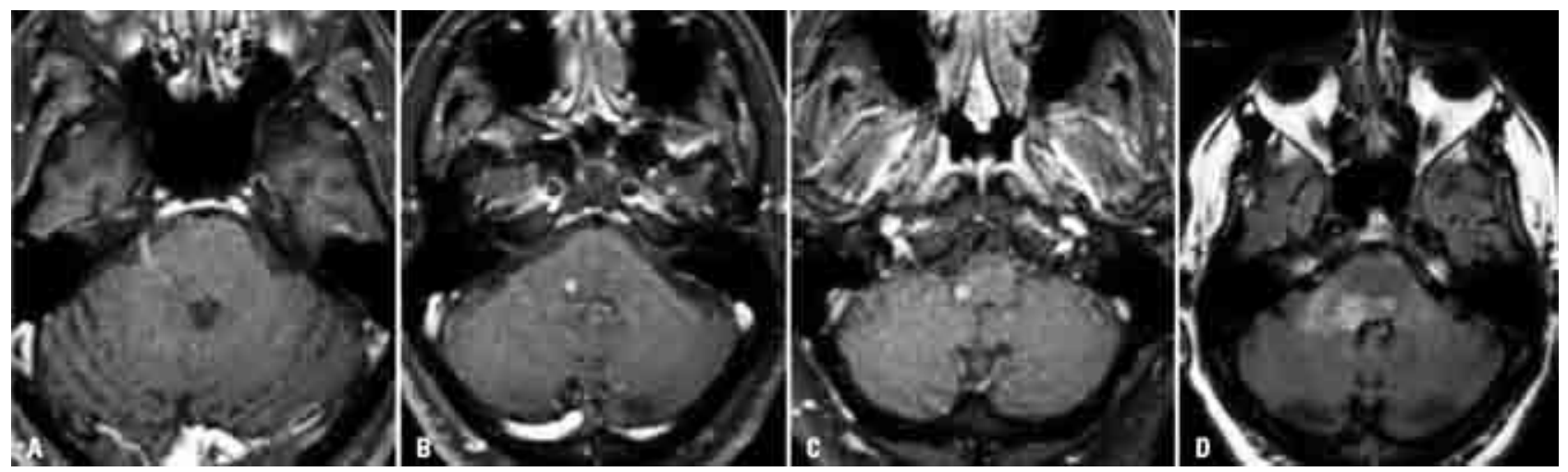

Figure. T1WI (A-C) demonstrates enhancement along right trigeminal nerve extending to spinal trigeminal nucleus ipsilaterally. Flair image (D) shows bilateral and asymmetric lesions in the brainstem. 
sions involving the brainstem and, as far as we know, such striking involvement of trigeminal nerve extending to its trigeminal spinal nucleus has never been reported. It may mimic trigeminal nerve involvement with herpes zoster.

For the treatment, ampicillin and gentamicin are the most recommended combination. Dexamethasone is an important agent in treating most CNS infection because of its powerfull anti-inflammatory activity and reduction of cerebral edema ${ }^{4}$.

Listeria monocytogenes encephalitis should be included in the differential diagnosis of rombencephalitis in elderly people with non-typical bacterial CSF founds. Involvement of trigeminal nerve and spinal trigeminal nucleus can occur in these cases, mimicking cases of herpes zoster infection.

\section{REFERENCES}

1. Kayaaslan BU, Akinci E, Bilen S, et al. Listerial rhombencephalitis in an immunocompetent young adult. Int J Infect Dis 2009;13:65-67.
2. Uldry PA, Kuntzer T, Bogousslavsky J, et al. Early symptoms and outcome of Listeria monocytogenes rhombencephalitis: 14 adult cases. J Neurol 1993;240:235-242.

3. Armstrong RW, Fung PC. Brainstem encephalitis (rhombencephalitis) due to Listeria monocytogenes: case report and review. Clin Infect Dis 1993; 16:689-702.

4. Popescu GA, Saquepe'e M, Poisson D, Prazuck T. Treatment difficulties of a listerial rhombencephalitis in an adult patient allergic to penicillins. J Clin Pathol 2004;57:665-666.

5. Alper G, Knepper L, Kanal E. MR Findings in Listerial rhombencephalitis. AJNR 1996;17:593-596.

ROMBOENCEFALITE CAUSADA POR LISTERIA MONOCYTOGENES COM ENVOLVIMENTO DO NERVO TRIGÊMIO NA RNM

Neurology Department, Hospital Governador Celso Ramos, Florianópolis SC, Brazil: 'Resident of Neurology; ${ }^{2}$ Resident of Neurosurgery; ${ }^{3} \mathrm{MD}$, Neuroradiologist, Associate Professor of Neurology Residency Program; ${ }^{4} \mathrm{MD}$, PhD, Neurologist, Neurology Residency Program Preceptor, Head of the Neurology Residency.

Correspondence: Adriana Moro - Rua Prefeito Antenor Mesquita 98/101 88015-150 Florianópolis SC - Brasil. E-mail: moro_adriana@yahoo.com.br

Received 26 February 2011. Received in final form 13 March 2011. Accepted 21 March 2011. 